\title{
Relações de poder e processo de descolonização na Reserva Indígena de Dourados, Mato Grosso do Sul: uma análise
}

Power relations and decolonization process in Indigenous reserve of Dourados, Mato Grosso do Sul (Brazil): an analysis

\section{Fabio Mura*}

* Universidade Federal da Paraíba - João Pessoa, PB, Brasil fabiomura64@gmail.com https://orcid.org/0000-0003-2840-6355

Alexandra Barbosa da Silva**

** Universidade Federal da Paraíba - João Pessoa, PB, Brasil alexandrabar01@gmail.com https://orcid.org/0000-0003-3900-5725

Rubem Ferreira Thomaz de Almeida***

${ }^{\star \star \star}$ Museu Nacional/Universidade Federal do Rio de Janeiro - Rio de Janeiro, RJ, Brasil rubemalmeida@gmail.com 


\title{
Resumo
}

Focando a formação e o desenvolvimento da Reserva Indígena de Dourados (Mato Grosso do Sul), o presente artigo centra sua atenção na conformação, naquele espaço, de uma estrutura de poder, bem como em seu recente questionamento, principalmente a partir da atuação do Ministério Público Federal. Ganha vida, com isso, um processo de descolonização, que acaba por ir minando os efeitos de uma política tutelar implementada pelo Estado brasileiro. Analisando tais fatos e processos históricos, mostrar-se-á a complexidade e a diversidade de interesses envolvidos nesse contexto, destacando o quanto é inoportuno, para sua compreensão, enveredar para uma abordagem centrada numa oposição indígenas/não indígenas, sendo, em alternativa, mais indicado considerar diversos níveis de escala de organização política - que vão da dimensão doméstica, passando pela formação de comunidades políticas locais, à manifestação de etnicidade e à conformação de comunidades de cooperação de natureza interétnica.

Palavras-chave: relações de poder; povos indígenas; Reserva Indígena de Dourados; descolonização.

\begin{abstract}
Focusing on the formation and development of the Indigenous Reserve of Dourados (Mato Grosso do Sul), this article centers on the conformation, in that space, of a power structure, as well as on its recent questioning, mainly based on the work of the Federal Public Ministry. With this, a decolonization process comes to life, which ends up undermining the effects of a tutelary policy implemented by the Brazilian State. Analyzing such historical facts and processes, the complexity and diversity of interests involved in this context will be shown, highlighting how inopportune it is, for their understanding, to move towards an approach centered on an indigenous / non-indigenous opposition, being, alternatively, more appropriate to consider different levels of scale of political organization - ranging from the domestic dimension, through the formation of local political communities, the manifestation of ethnicity and the formation of interethnic cooperation communities.
\end{abstract}

Keywords: power relationships; indigenous people; Dourados Indigenous Reserve; decolonization. 


\section{Introdução ${ }^{1}$}

Num texto de caráter metodológico, A. Cicourel (1975) ressaltava o fato de que os resultados de um estudo são diretamente caudatários das condições da obtenção de seus dados. Era, portanto, fundamental que tais condições fossem explicitadas, não como algo residual, mas sim como parte constitutiva da própria análise. Pode-se dizer que essa proposta apresenta uma especial relevância para o presente artigo. As condições de sua realização, de fato, são inerentes à natureza do que lhe deu origem: o trabalho de consultoria de seus autores para órgãos públicos. O potencial analítico que aqui se poderá ler, portanto, é proveniente de pesquisa diretamente desenvolvida a partir de desafios e demandas concretas postas por indígenas a esses órgãos.

De fato, em inícios dos anos 2000 chegavam ao Ministério Público Federal (MPF) da cidade de Dourados (Cone Sul de Mato Grosso do Sul) diversas denúncias de violências e outras formas de subjugação. Partiam de indígenas kaiowa e ñandéva ${ }^{2}$ da reserva também de Dourados e referiam-se igualmente à falta de atendimento pela Fundação Nacional do Índio (Funai), bem como à falta de acesso à terra na reserva. Alguns anos mais tarde, um alarmante número de mortes por desnutrição de crianças (sobretudo kaiowa) nessa mesma reserva

1 Muito infelizmente, o caro colega Rubem F. T. de Almeida veio a falecer em julho de 2018. O presente artigo, no entanto, é resultado de uma longa cooperação entre nós, autores, incluindo a elaboração conjunta para fins de um livro sobre a Reserva Indígena de Dourados - o qual restou inacabado. Ficaram, no entanto, algumas reflexões que pudemos fazer juntos, sendo o cerne delas aqui expresso.

2 Na literatura clássica sobre esses indígenas, tanto os Kaiowa quanto os Ñandéva são considerados como grupos (ou subgrupos) Guarani (Melià; Saul; Muraro, 1987). Ocorre, porém, que os Kaiowa não aceitam a denominação de "guarani", apenas os Ñandéva e os Mbya se consideram como tal no Brasil. Para buscar superar esse impasse, quando se refere a todos estes grupos em conjunto, Barbosa (2014) propõe a denominação genérica de "povos de fala guarani", escolha que parece feliz. Por outro lado, se tratamos esses coletivos cotejados uns em relação aos outros, essa denominação genérica se mostra de pouca utilidade, uma vez que não permite destacar as especificidades de cada um destes. No caso específico tratado aqui, referindo-se a Mato Grosso do Sul e levando em consideração um público amplo (não necessariamente especialista sobre esses indígenas), optamos por utilizar a denominação Ñandéva, evitando falar simplesmente "Guarani". Com isso justamente somos mais específicos, diferenciando-os tanto dos Kaiowa quanto dos Mbya - com os quais, contudo, compartilham semelhanças de organização social, política, cosmológica e linguística. Já no que tange à pronúncia das palavras, de um modo geral, na fonética guarani há a tendência para que o acento tonal recaia sobre a última sílaba das palavras, de forma que, quando não acentuadas, as palavras são oxítonas. 
levava o então Ministério de Desenvolvimento Social e Combate à Fome (MDS) à liderança de um "Comitê Gestor" interministerial, criado para dar conta da situação. Foi nesse quadro que se originou uma demanda por consultoria antropológica, com levantamentos ad hoc e consequente elaboração de relatórios. Os intentos foram, por um lado, averiguar a situação que tinha gerado as denúncias indígenas e, por outro, possibilitar o processo de implementação do programa governamental chamado Bolsa Família.

Como antropólogos, ficava muito clara a necessidade de, com base num conhecimento acumulado ao longo do tempo, em diversas aldeias kaiowa e ñandéva no estado, observar a situação política que ali tinha vida, bem como a forma como então se apresentava a organização social desses indígenas especificamente na reserva de Dourados. Só assim seria possível melhor compreender o contexto a partir do qual se tinham gerado as denúncias.

No foco das questões postas aos órgãos públicos colocava-se a reivindicação pelo reconhecimento público de mais de 40 lideranças kaiowa e ñandéva, que estariam à frente de um igual número de grupos, internamente à reserva. O pleito comum era o de serem todos atendidos com uma distribuição de recursos, que então justamente estavam concentrados em fundamentalmente duas lideranças (os capitães). Por encomenda do MPF, foi então realizado um diagnóstico situacional na reserva. ${ }^{3}$ Já para a implementação do Bolsa Família, essa situação política foi compreendida como importante de ser aprofundada, até mesmo para verificar uma eventual relação sua com as mortes infantis por desnutrição.

Como se pode vislumbrar, para além dos dados gerados nas pesquisas, o próprio caráter que o trabalho de consultoria teve é fundamental no presente artigo, sendo parte constitutiva mesma dos eventos, vindo a ser determinante para mudanças que se implementariam posteriormente na reserva. ${ }^{4}$

3 O relatório que contém esse diagnóstico situacional permaneceu por diversos anos sob sigilo, sendo restrito aos procuradores do MPF-Dourados. Isso porque ali se encontravam relatos de denúncias, bem como os nomes dos denunciantes, e sua divulgação poderia expor essas pessoas a possíveis ameaças e represálias. Em decorrência disso, do ponto de vista ético e metodológico, também neste artigo optamos por não utilizar os relatos, nem sequer com uso de pseudônimos, visto que ainda assim haveria a possibilidade de identificação das pessoas que na época realizaram as denúncias.

4 Embora fosse interessante uma discussão sobre o papel e lugar da intervenção prática a partir de conhecimento antropológico, esse não é o intento aqui. 
Diante desse preâmbulo contextualizador, o intento aqui é apresentar e analisar como historicamente pode se concretizar uma estrutura de poder centralizada no coração de uma reserva indígena, e suas consequências para uma organização sociopolítica descentralizada e todo um modo de vida a ela relacionado. Um segundo movimento será o de focar num processo de transformação dessa estrutura, que aqui será avaliado como de descolonização. O ganho teórico está em se refutar uma apriorística "visão unificada do mundo social" (Bensa, 1998), a qual, compreendemos, instituiria uma realidade indígena abstrata e para sempre igual a si mesma.

O desenvolvimento do exercício se dará considerando um processo histórico como tal: aquele desenvolvido na reserva de Dourados. Para isso falaremos inicialmente da criação dessa unidade administrativa, instituída pelo então Serviço de Proteção aos Índios (SPI), remetendo depois à emergência e consolidação de uma estrutura de poder na reserva, seguida do desencadear-se de um processo de descolonização. Já num último item, teceremos reflexões a respeito de povos indígenas e relações de poder. Cabe esclarecer que os dados trazidos são os presentes nos relatórios de pesquisa mencionados e, quando não for assim, isso será explicitado no texto.

Passemos, então, à descrição e análise.

\section{Criação da reserva de Dourados}

Para compreender como foi criada e se desenvolveu ao longo do tempo a reserva de Dourados é necessário dirigir o olhar para o quadro histórico e de configuração territorial que antecede a sua instituição.

Após o conflito bélico entre Brasil e Paraguai - no contexto da chamada Guerra da Tríplice Aliança (1864-1870) - e em decorrência da redefinição dos limites entre esses dois Estados, foram definidas políticas de ocupação, exploração e controle dessa faixa fronteiriça. Num primeiro momento, todo o Cone Sul do atual estado de Mato Grosso do Sul, território tradicionalmente ocupado pelos indígenas de língua guarani (Kaiowa e Ñandéva), foi entregue como concessão exclusiva nas mãos de uma empresa, a Companhia Matte Larangeiras (Brand, 1997; Chamorro, 2015; Thomaz de Almeida, 1991; Vietta, 2007). O intuito era explorar os extensos ervais aí presentes. Durante o período que vai até a 
segunda década do século $\mathrm{XX}$, os indígenas da região foram sistematicamente engajados como trabalhadores braçais pela companhia. Contudo, não sendo proprietária das terras, mas apenas concessionária, a empresa não produziu a expropriação territorial dos Kaiowa e dos Ñandéva, algo que veio a se concretizar apenas nas décadas seguintes. Com efeito, a perda do monopólio sobre esses espaços, nos anos 1920, deu vida a uma progressiva ocupação do então estado de Mato Grosso por frentes migratórias, procedentes primeiro do sul do Brasil e posteriormente dos estados de São Paulo e Minas Gerais, que vieram a formar fazendas, fundamentalmente de gado.

O início desse processo evidenciou para o Estado brasileiro a situação dos indígenas, até então engajados nos ervais. Assim, o então Serviço de Proteção aos Índios e Localização de Trabalhadores Nacionais (SPILTN), criado em 1910 no seio do Ministério da Agricultura, teve um papel fundamental na criação de reservas indígenas em Mato Grosso. Ao mesmo tempo em que as delimitava (sempre com tamanhos não superiores a 3.600 hectares), também liberava amplos espaços para a colonização e o controle da faixa fronteiriça por não indígenas (Souza Lima, 1995). Há que se observar que, embora em 1917 o órgão indigenista abandone o Ministério da Agricultura e se torne apenas "SPI", sua política continuou sendo, complementarmente, a de colonização. Foi justamente no bojo dessa política que, especificamente nessa região foram criadas, entre 1915 e 1928, oito reservas, destinadas a aldear os Kaiowa e os Ñandéva que até então ali viviam dispersos.

Dourados foi a segunda dessas oito reservas, sendo instituída em 1917, no então distrito homônimo do município de Ponta Porã. Com o tamanho de 3.550 hectares, ali foi sediado um Posto Indígena, batizado com o nome de um inspetor do SPI, o coronel Francisco Horta Barboza (ver Figura 1).

Como era comum nas escolhas do SPI para criar e delimitar as reservas, não era utilizado qualquer critério centrado no conhecimento sobre a organização social e territorial dos povos indígenas. Dourados não foi uma exceção. Como colocam em evidência Thomaz de Almeida e Mura (2003), a reserva é despossuída de fontes significativas de água, não sendo, por tal motivo, um espaço que teria sido escolhido pelos indígenas como lugar onde concentrar as habitações de todas as suas parentelas. Com efeito, como explicam os próprios Kaiowa, esse lugar seria parte de um bem mais amplo território, configurado nos espaços desenhados pela bacia dos rios Brilhante e 
Ivinhema. ${ }^{5}$ As ramificações fluviais aí existentes permitiam uma distribuição distanciada das parentelas, que assim configuravam comunidades políticas locais, relativamente autônomas - configurações essas que, a partir dos anos 1970, passaram a ser denominadas de tekoha (Barbosa; Mura, 2011; Mura, 2019; Thomaz de Almeida; Mura, 2004). Quando de sua criação, nos espaços da reserva residiam poucas parentelas, sendo a maior parte de sua superfície caracterizada pela presença de mata alta e densa, com excelentes qualidades agronômicas, que era utilizada pelos indígenas mais que tudo para atividades venatórias e, principalmente, para agricultura.

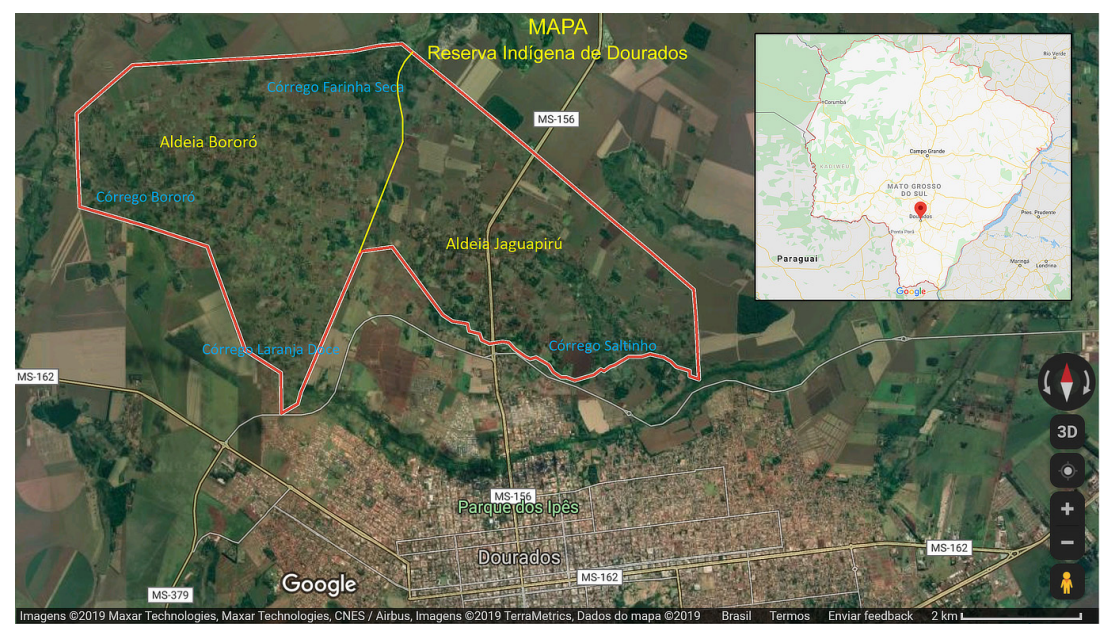

Figura 1. Mapa da Reserva Indígena de Dourados. Fonte: Google Maps.

5 Monteiro (2003) traz documento sobre a chegada do capuchinho Angelo de Caramonico à colônia militar de Dourados, em 1863. O missionário intentava atrair os indígenas das redondezas para o aldeamento implantado na confluência dos rios Santa Maria e Brilhante. Esse aldeamento, no entanto, teve curtíssima existência devido às atribulações deflagradas pela guerra, no ano seguinte, e os índios que ali estavam se dispersaram. Já no período varguista do Estado Novo, a colonização de caráter público alcançou visibilidade na região com a Colônia Agrícola Nacional de Dourados (Cand), estabelecida, em 1943, em terras de ocupação kaiowa (sobretudo as localidades de Panambi e Panambizinho). Com cerca de 300.000 hectares, a Cand tinha como objetivo a instalação dos colonos em áreas de pequena propriedade (lotes de cerca de 30 hectares cada um), estimulando o desenvolvimento de uma agricultura baseada no trabalho familiar. As terras foram distribuídas principalmente para famílias nordestinas, mas também paulistas e mineiras. Sobre a Cand, ver Fernandes Silva (1982). O estabelecimento dessa colônia gerou atritos e uma disputa que se arrastou durante décadas, sobretudo entre os colonos e os indígenas de Panambizinho, sendo que apenas no final de 2004, com a participação do Instituto Nacional de Colonização e Reforma Agrária (Incra) e a atuação do MPF de Dourados, houve uma transferência dos colonos para outro local. 
O intuito com a criação da reserva pelo SPI, porém, era outro. Através da implementação de práticas agrícolas tinha-se a intenção de transformar paulatinamente os indígenas que foram ali concentrados em "trabalhadores nacionais" e, consequentemente, "integrá-los" e "assimilá-los" à sociedade nacional, fato que ficou evidente nas décadas seguintes à criação da reserva. Para tal propósito, alguns aspectos da morfologia social (Mauss, 1993) dos Kaiowa e dos Ñandéva eram vistos como vantajosos como base para promover essas atividades agrícolas, conforme as observações do coronel Estigarribia. Em documento de 22.01.1926 (Estigarribia, 1926) este afirmava: “[...] como a terra em Dourados é muito boa, seria conveniente conservar as habitações dispersas dos índios, figurando cada uma delas como um sítio, cujo lote a Inspetoria mandará demarcar [...]".

Ainda nessa intenção de aprimorar a agricultura, no começo dos anos 1920 os funcionários do SPI deslocaram para o local famílias indígenas terena, procedentes de regiões mais ao norte, com a declarada intenção de "educar" os Kaiowa e os Ñandéva para um estilo de vida "mais civilizado" (Thomaz de Almeida; Mura, 2003). Os Terena, de fato, se apresentavam aos olhos desses agentes como mais aptos a desenvolverem uma agricultura tida como eficiente. Isso talvez devido à prática desses indígenas de destocar, quando das derrubadas das matas para a produção agrícola (cf. Ladeira; Azanha, 2018). Já os Kaiowa e os Ñandéva, embora exímios agricultores, com experiência milenar, por seu método baseado na coivara, de não destoque e de rotatividade de espaços para roçado, assim como devido a seus padrões de assentamento e de mobilidade, eram tidos pelos agentes do SPI como tecnicamente pouco produtivos. Nesse sentido, pensava-se que o convívio com os Terena favoreceria mudanças comportamentais, aproximando-os inclusive da "civilização".

Assim, a essa primeira leva de famílias terena, o SPI favoreceu algumas outras em direção a Dourados. Já no levantamento em campo, constatou-se que algumas famílias haviam chegado na reserva na década de 1960. Em meio a esse processo, cabe destacar um episódio ainda do ano de 1923, que, como veremos no próximo item, terá significativas consequências décadas depois. Ocorre que um funcionário do SPI, Romualdo Rodrigues Ferreira, sendo expulso do

6 Em sua visita a Dourados nos anos de 1950, Roberto Cardoso de Oliveira (1976) menciona a existência dessa divisão em lotes, que ainda se manterá ao longo da década de 1970. 
órgão indigenista por atividades ilícitas, resolveu sair da região de Buriti, localizada mais ao norte, em território terena, para refugiar-se justamente na reserva de Dourados. Ele teria levado e liderado um grupo de pessoas cujas identidades vinham relatadas nos documentos da época de forma diversificada. Pimentel Barboza (1923, p. 13), um dos auxiliares do SPI, em um relatório dirigido à Inspetoria Regional do órgão indigenista, definindo Romualdo como "um correntino" (isto é, de Corrientes, Argentina) e desqualificando seu grupo como sendo indígena, com exceção de um indivíduo, afirmou: “... [o] grupo de Romualdo, tantas vezes chamado de índios e que no entanto de índio só tinha o infeliz Terena...”. Por outro lado, um relatório policial, que acompanha aquele de Pimentel Barboza, considerava também como indígenas outros membros desse grupo. De qualquer forma, ficava apontada uma configuração interétnica daquele conjunto de pessoas, que possivelmente algum vínculo tinham entre si.

A atuação de Romualdo não se limitou à reserva de Dourados - como veremos logo abaixo; antes, porém, importa observar o que Lourenço (2019, p. 62) apresenta:

Segundo relatório do SPI de 1924, mais de cem índios Terena, provindos das aldeias da região de Aquidauana e Miranda, teriam ido trabalhar na construção das linhas telegráficas em Ponta Porã (MUSEU DO ÍNDIO, SPI, 1924, MF. 379, FG. 1503). Desse modo, um novo contingente de Terena teria sido encaminhado para a Reserva de Dourados quando do fim da construção da linha telegráfica, pois alguns deles não mais retornaram para suas regiões de origem.

Como se vê, em relatório posterior em um ano ao de Pimentel Barboza é descrita outra migração terena. ${ }^{7}$ No meio-tempo, o referido Romualdo tentou buscar espaços nos arredores da reserva, com o intuito de explorar economicamente a erva-mate da região. Especificamente em Dourados, entrou em embate com a parentela kaiowa ali mais expressiva, em termos políticos e numéricos, representada pelos Fernandes. Para isso, buscou se aliar com famílias kaiowa

7 De modo mais claro, segundo um trabalho de 2008 de Lourenço, a passagem de Rondon por aldeias terena do Bananal (em Aquidauana) o fez notar a habilidade de ler e escrever de várias pessoas ali, estimulando, então, o deslocamento para Dourados das cem pessoas acima referidas (cf. Lourenço, 2008 apud Cariaga, 2019, p. 241). 
e ñandéva rivais dessa parentela. Contudo, há que se considerar que até o final dos anos de 1950 os Fernandes conseguiram manter o controle da reserva, com sua situação territorial sendo assim descrita por Cardoso de Oliveira (1976, p. 86-87) depois de uma visita ao lugar:

A reserva [...] é ocupada preponderantemente por índios Guarani, do subgrupo Kaiwá, que se distribuem em três dos quatro núcleos populacionais da aldeia: a) o núcleo central ou Aldeia Farinha Seca, onde fica a moradia do "Capitão" Kaiwá, João Fernandes, nas proximidades do Posto Indígena, e onde também mora a maioria da população Kaiwá; b) a Aldeia Bororó, como a denomina seu grupo de 177 índios Kaiwá, concentrados às margens do córrego São Domingos e que possui o próprio chefe, o "Capitão" Ireno Isnardi; c) também a Aldeia Potrerito, subjacente à anterior, formada por apenas 4 ranchos, com 10 habitantes Kaiwá, às margens do córrego do mesmo nome; finalmente, d) o quarto núcleo, o Jaguapiru, constituído exclusivamente por famílias Terena, que compreendem cerca de 180 pessoas, distribuídas em ranchos ao longo do córrego Saltinho ou Jaguapiru.

Como se revela na descrição, Dourados possuía na época quatro comunidades locais, com os Terena ainda morando nas proximidades do córrego Jaguapiru (ou Saltinho). Na margem da reserva indígena, esse era um espaço caracterizado pela presença de pedras e por menor qualidade agronômica quando comparado a outros locais da mesma reserva. Será a expansão dos Terena em direção ao centro da reserva que levará, nas décadas seguintes, a diminuta aldeia de Jaguapiru a se tornar a metade da reserva como um todo, passando a se estabelecer uma divisão entre ela e aquela que será então denominada aldeia Bororó.

A população na reserva começou também a aumentar significativamente a partir da década de 1960, com uma aceleração no crescimento demográfico nos anos 1970, algo que será sobremaneira significativo na configuração territorial dessa terra indígena/reserva. Como indicado, algumas famílias terena se acresceram às já ali presentes, permitindo a ampliação do contingente de pessoas pertencentes a esse grupo étnico. Mas o maior aumento deveu-se à chegada de parentes dos Kaiowa e de uma minoria ñandéva, expulsos de seus lugares de origem, localizados principalmente na bacia dos rios Brilhante e Ivinhema. Afluíram também outras famílias kaiowa, procedentes já de uma 
região localizada a oeste da reserva, denominada hoje de Lima Campo pelos indígenas (Barbosa da Silva, 2007). Tais expulsões foram devidas principalmente aos efeitos da implementação de uma política de Estado desenvolvida a partir de meados dos anos 1960, direcionada a mecanizar a agricultura e promover o que passou a ser conhecido como o "milagre brasileiro". Tal política levou a um intenso desmatamento, com vistas à produção extensiva da soja, tendo como consequência a expulsão das famílias que então estavam nos "fundos de fazenda" (Thomaz de Almeida, 2001). Assim, o desmatamento e a expulsão a partir dos anos 1970 produziram um inchaço, praticamente duplicando-se a populaçãoem Dourados, com intensa reverberação ainda nos anos 1980 - cf. o Quadro 1, apresentado adiante.

\section{A emergência e consolidação de uma estrutura de poder na reserva}

O ímpeto desenvolvimentista que transformou a paisagem no extremo sul do atual Mato Grosso do Sul não se limitou às fazendas da região; a modernização da agricultura foi utilizada como modelo também para as políticas nas reservas indígenas. Na década de 1970, dando continuidade à ideologia integracionista herdada do extinto SPI, a Funai resolveu promover os denominados "Projetos de Desenvolvimento Comunitário" (PDC), buscando introduzir como principal meio de mecanização o trator, além de promover, onde possível, o cultivo da soja - alimento que era alheio à dieta indígena e regional, destinado à exportação internacional.

Como observa Fernandes Silva (1982), a experiência de uma condução centralizada, organizada diretamente pela Funai nas diminutas áreas indígenas kaiowa de Panambizinho e Panambi (nas proximidades da reserva de Dourados), levou progressiva e rapidamente ao fracasso dos PDC, uma vez que estes eram sistematicamente esvaziados de mão de obra indígena pelos próprios Kaiowa que aí residiam.

Na reserva de Dourados, contudo, a experiência teve resultado diferente. Em primeiro lugar, a chegada de um novo "chefe de posto", em 1974, levou a algumas mudanças na organização política local. Esse chefe escolheu dois jovens indígenas para ocupar cargos de capitães, possibilitando assim 


\begin{tabular}{|c|c|c|c|c|c|c|c|c|}
\hline$\stackrel{+}{\infty}$ & $\begin{array}{l}\text { ֻै } \\
\stackrel{1}{\rightarrow}\end{array}$ & $\stackrel{\stackrel{2}{N}}{=}$ & 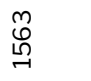 & $\begin{array}{l}\stackrel{\infty}{\infty} \\
\text { m }\end{array}$ & $\stackrel{\stackrel{\sim}{N}}{\text { m }}$ & 공 & $\overrightarrow{\vec{N}}$ & $\begin{array}{l}\stackrel{2}{人} \\
0 \\
0\end{array}$ \\
\hline $\begin{array}{l}m \\
\infty \\
\stackrel{-}{-}\end{array}$ & $\begin{array}{l}\llcorner \\
\infty \\
0\end{array}$ & $\stackrel{9}{\circ}$ & 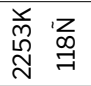 & & fे & & 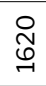 & ஓ \\
\hline$\stackrel{\text { ळ్ }}{\stackrel{-}{\sigma}}$ & 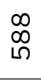 & $\underset{\text { O }}{0}$ & 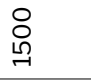 & $\stackrel{\sim}{N}$ & $\hat{\overrightarrow{0}}$ & ஜ̊ & 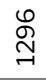 & $\stackrel{\stackrel{N}{N}}{m}$ \\
\hline 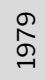 & 옴 & न & ঃ & & $\underset{\substack{0 \\
\infty \\
\sim}}{-1}$ & $\underset{\infty}{\stackrel{\Delta}{\infty}}$ & 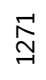 & $\stackrel{\circ}{\stackrel{2}{N}}$ \\
\hline 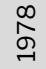 & 옴 & 8 & & & & ণิ & & \\
\hline م & 옴 & ○ & & & & $\begin{array}{l}\infty \\
\overrightarrow{6}\end{array}$ & & \\
\hline $\begin{array}{l}0 \\
\stackrel{2}{9} \\
\stackrel{-1}{-1}\end{array}$ & กิ & oิ & 8 & & & 요 & & $\stackrel{+}{\underset{N}{N}}$ \\
\hline$\stackrel{\stackrel{\circ}{\Omega}}{\stackrel{9}{\sim}}$ & 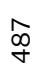 & बึ & & & & 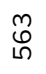 & & $\stackrel{\infty}{\sim}$ \\
\hline 皿 & $\stackrel{\infty}{+}$ & $\underset{\text { n }}{N}$ & & & & 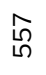 & & $\underset{ }{ }$ \\
\hline$\stackrel{m}{\stackrel{n}{\sigma}}$ & $\stackrel{\mathfrak{Z}}{\forall}$ & & & & & $\begin{array}{l}0 \\
\tilde{N}\end{array}$ & & \\
\hline$\underset{\sim}{\stackrel{N}{N}}$ & กิ & & & & & ১ & & \\
\hline 点 & $\hat{\vartheta}$ & $\stackrel{\circ}{\vec{m}}$ & กิ & & & $\underset{\forall}{\vec{\gamma}}$ & & ণิ \\
\hline 옹 & $\hat{\vartheta}$ & $\stackrel{\circ}{m}$ & Nิ & & $\hat{\vartheta}$ & $\stackrel{-}{m}$ & ஸ̃ & ণิ \\
\hline $\begin{array}{l}\mathscr{9} \\
\stackrel{6}{్}\end{array}$ & & & & & & $\stackrel{\infty}{\stackrel{\infty}{m}}$ & & \\
\hline $\begin{array}{l}\stackrel{\infty}{0} \\
\stackrel{్}{\sigma}\end{array}$ & & & & & & $\overrightarrow{\text { ㄱ }}$ & & \\
\hline ڤ్ & & & & & & $\vec{\sim}$ & & \\
\hline $\begin{array}{l}\stackrel{2}{0} \\
\stackrel{\leftrightarrow}{-}\end{array}$ & & ôm & $\underset{\sim}{\stackrel{J}{*}}$ & $\vec{m}$ & $\stackrel{L}{m}$ & $\stackrel{+}{\stackrel{N}{N}}$ & $\underset{\infty}{\infty}$ & 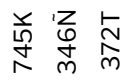 \\
\hline 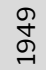 & O্ & ঃ & $\stackrel{\circ}{\circ}$ & & $\stackrel{?}{\stackrel{f}{f}}$ & $\stackrel{\substack{n \\
m}}{n}$ & 음 & $\stackrel{\infty}{\text { Lे }}$ \\
\hline 今 & 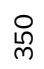 & $\stackrel{\circ}{\stackrel{\circ}{N}}$ & $\stackrel{\circ}{\mathrm{N}}$ & & & ํㅗ & & \\
\hline & 音 & 융응 & 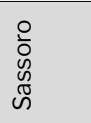 & 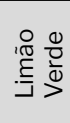 & 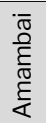 & 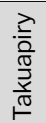 & 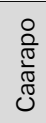 & 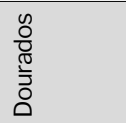 \\
\hline
\end{tabular}


que se concluísse um processo que redundaria na divisão da reserva nas já mencionadas aldeias de Jaguapiru e Bororó. Para representar a primeira aldeia, optou pelo membro de uma família terena que havia chegado na década de 1920 em Dourados, integrando o grupo de Romualdo. Num relatório da Funai relativo ao Posto Indígena de Dourados (Barros; Costa Telles, 1974), é informado que a escolha de um capitão terena buscava diminuir tensões existentes na reserva entre as famílias pertencentes a esse grupo étnico e algumas famílias kaiowa e ñandéva ali residentes. Ocorre, porém, que essa medida se revelou pouco eficaz para esse específico propósito, uma vez que o conflito perdurou. ${ }^{8}$

Os efeitos mais marcantes da escolha desse capitão foram outros, relacionados às intenções de "desenvolvimento" da aldeia, no sentido antes descrito de uma modernização das atividades agrícolas. Para essa tarefa, esse capitão pôde contar com um trator oriundo da Igreja Metodista de Dourados, que possuía um programa para o desenvolvimento comunitário em terras indígenas. ${ }^{9} \mathrm{Em}$ uma planilha constante do relatório de Valle (1975, p. 24), voltado à definição de um "projeto de desenvolvimento comunitário no Posto Indígena Dourados", são apresentados os 23 beneficiários do programa dessa igreja, com pessoas terena sendo a maioria; entre essas, a que obteve maior produção de soja foi justamente o então recém-nomeado capitão. Há que se observar que um dos critérios para a obtenção do financiamento era que se possuísse terra destocada, algo que, como vimos, os Kaiowa e os Ñandéva não faziam. Conforme argumentaram Thomaz de Almeida e Mura (2003, p. 41), esses seriam

[...] critérios nos quais os Kaiowa e Ñandeva dificilmente se encaixariam mesmo nos dias de hoje. Como não poderia deixar de ser, "por esses critérios a maioria dos associados recaiu sobre os Terena" (Barros, 1974). Pode-se dizer que aqui está

8 Em tempos mais recentes, Cariaga (2019) também apresenta, em sua pesquisa, as marcas desse conflito na reserva.

9 Este se deu através do "Plano de Promoção Social do Índio", desenvolvido pela Ação Social da Igreja Metodista de Dourados, a partir de 1971, iniciativa que pode ser considerada a primeira a oferecer (até mesmo antes da Funai), no MS, apoio financeiro em "programas de desenvolvimento" para os indígenas. Segundo Thomaz de Almeida e Mura (2003, p. 41): "O objetivo desse Plano era fomentar a produção agrícola em Dourados, financiando o necessário, de trator a sementes, para as roças; os recursos investidos deveriam ser pagos na colheita a juros de 0,5\%. Os Metodistas contavam para realizar o seu trabalho em 1973, com três tratores, moto-serra, pulverizadores, além de fornecer ferramentas de trabalho aos associados." 
o princípio da estrutura política, econômica e social que se instalou naquela localidade [...].

Segundo informa Barros (1974) em seu relatório sobre o Posto Indígena de Dourados, com o aval do pastor da igreja, o capitão também adquiriu equipamento para pulverização de agrotóxicos, ampliando sua infraestrutura e suas possibilidades de empreendimentos econômicos na reserva. A esses equipamentos de uso particular viria se somar outro trator, dessa vez introduzido pela própria Funai, dando-se impulso significativo à expansão do plantio da soja no local. Assim, essas iniciativas, ocorridas nos anos 1970, estão justamente na origem da formação de uma estrutura de poder que perdurará por décadas e que teve significativos efeitos organizacionais em Dourados.

Em primeiro lugar, para permitir a expansão da soja, ainda nos anos 1970 e 1980 foi promovido pelo órgão indigenista um intenso desmatamento da reserva, possibilitando que as famílias terena que anteriormente estavam assentadas nas margens do córrego Jaguapiru se expandissem em direção ao centro da atual aldeia de Jaguapiru; algumas inclusive se localizaram na divisa com a contígua aldeia Bororó. Essa atividade de desmatamento garantiu também para o posto indígena lucros com a venda da madeira procedente das derrubadas. A destoca, como prática recorrente seguida ao desmatamento (cf. Barros, 1974), também comprometia a recuperação da vegetação nativa, mudando progressivamente e quase que de forma irreversível a paisagem do lugar.

Em segundo lugar, seguido a esse intenso processo - que, como visto, se somou ao marcante aumento da população na reserva - houve uma ulterior divisão do espaço físico. Assim, se desde a sua instituição o SPI havia demarcado lotes (de aproximadamente 30 hectares) na reserva, em decorrência da falta de espaço, em muitos casos (mas não em todos, o que será relevante, como veremos) estes passaram a ser divididos em áreas bem menores, denominadas de "datas". Estas estão muito mais próximas das dimensões de espaços urbanos do que daqueles rurais, inviabilizando a produção ou tornando-a escassa em termos agrícolas. O plantio, nesses espaços, de mandioca e milho, consorciados com outras plantas alimentares, passou a ser insuficiente e proporcionalmente muito oneroso em termos de preparação do solo, uma vez que a paisagem, quando não dominada pela soja, tornou-se caracterizada pela presença de 
plantas daninhas - como as pastagens de origem africana, de difícil extirpação sem o uso de meios mecanizados.

Como consta das informações levantadas entre os Kaiowa e os Ñandéva do local (Thomaz de Almeida; Mura, 2003), isso em algumas ocasiões levou famílias a arrendarem suas diminutas terras para os que plantavam soja, em troca de pagamentos antecipados, recaindo assim muitas vezes num endividamento continuado. Tais dívidas teriam frequentemente não sido pagas, perdendo-se, consequentemente, a terra. Os efeitos dessas dinâmicas foram a produção de uma estrutura fundiária bastante complexa, com uma grande variação de tamanho nas posses das famílias, com algumas podendo ampliar seus espaços de domínio e, com isso, sua opulência técnica, econômica e política. Outras, ao contrário, perderam cada vez mais espaço, com as mais penalizadas sendo constrangidas a morar, como dizem os próprios indígenas, "embaixo d'água" em referência aos lugares que margeiam o córrego Jaguapiru, os quais, além de caracterizados pela presença de pedras (que dificultam a agricultura), são também áreas alagadiças.

Em terceiro lugar, em decorrência desse inchaço populacional e da pouca terra disponível para satisfazer as necessidades de muitas famílias, Dourados de fato veio a tornar-se um conspícuo reservatório de mão de obra. Muitos homens passaram a ser contratados para trabalhar nas usinas de álcool localizadas no vizinho oeste de São Paulo e, a partir dos anos 2000, com a política de incentivo ao etanol como combustível, no próprio Mato Grosso do Sul. Esse fenômeno caracterizou não apenas Dourados, mas quase a totalidade das terras indígenas do estado, mobilizando milhares de pessoas (Ferreira, 2019; Mura; Barbosa da Silva, 2019). Porém, pelo fato de ser a mais populosa, Dourados teve um contingente muito grande de pessoas dirigidas para esses lugares, envolvendo muitos interesses locais, pela quantidade de recursos financeiros que possibilitava. Ocorre que, como descrito e analisado em outro lugar (Mura; Barbosa da Silva, 2019), em torno dessa mobilização de mão de obra foi construído em Mato Grosso do Sul um sistema específico que, além dos trabalhadores, envolvia três figuras interessadas nesse processo: o(s) capitão(ães) das aldeias; os intermediários entre os indígenas contratados e as usinas (chamados de "gatos"), muitas vezes sendo estes os próprios capitães; e comerciantes locais. Os contratos de trabalho não eram realizados de forma individual, mas coletiva, decisão tomada envolvendo a Funai e o Ministério Público do Trabalho e tendo 
implicações significativas. Essas envolviam diretamente a atuação dos capitães, que acabaram sendo os destinatários dos recursos arrecadados, através daquilo que foi estipulado como "taxa comunitária" - retirada de cada trabalhador e que deveria supostamente formar um fundo, para atender as necessidades de cada terra indígena. Há que se observar que, diferentemente do cargo de funcionário da Funai, aquele de capitão não era formalmente remunerado, sendo, então, o arrecadamento da "taxa" fonte das críticas das famílias indígenas não aliadas do capitão de turno. Essas denunciavam o uso, seja para interesses particulares dos capitães, seja de parentes seus ou de famílias com quem este mantinha relações políticas e/ou econômicas.

Os comerciantes locais, por sua vez, reproduzindo o clássico esquema de aviamento, caracterizado pela lógica do barracão (Pacheco de Oliveira, 1988; Peres, 2018), adiantavam recursos para o trabalhador, mantendo-o em continuada dependência, muitas vezes retendo (ilegalmente), como garantia de pagamento, os cartões do banco através dos quais os indígenas que iam para as usinas recebiam seus salários.

Para finalizar este item, cabe ainda ressaltar que os efeitos da estrutura de poder construída em Dourados a partir dos anos 1970 não foram peculiares a essa reserva. Contudo, pela magnitude da população que alcançou, bem como pelas características (estas sim específicas de Dourados) de ter sido formada por grupos terena, kaiowa e ñandéva, tais efeitos implicaram diferentes atitudes e envolvimentos das famílias indígenas frente às possibilidades que surgiam, em decorrência principalmente da implementação de políticas integracionistas e desenvolvimentistas por parte do Estado. Não parece um acaso que em fins dos anos 1990 e começo dos anos 2000 - quando se avolumaram denúncias para o MPF contra essa estrutura de poder e o nada democrático atendimento na reserva por parte da Funai - estava como capitão na reserva aquele mesmo Terena que na década de 1970 iniciara sua ascendência socioeconômica na aldeia, sendo que ao cargo de capitão viera a se somar aquele de "gato". Concomitantemente, um irmão seu havia sido nomeado chefe de posto e outro ainda chefe do Núcleo Indígena de Dourados (uma base operacional, na cidade de Dourados, da Administração Executiva Regional da Funai, localizada no município de Amambai). Tal sistema de poder não se limitava à aldeia Jaguapiru, envolvendo também a de Bororó, uma vez que o que estava em jogo era a manutenção das lógicas de representação política e de seu reconhecimento por parte 
da Funai. Tampouco, aqui, revela-se um acaso que na aldeia de Bororó estivesse no poder, na qualidade de capitão, um Kaiowa, relacionado por laços de afinidade com a parentela kaiowa que mais se afirmou nesse lugar, em decorrência das alianças historicamente realizadas com os Terena que mais êxito tiveram em Jaguapiru.

É de se dizer, ainda, que as dissimetrias relacionais fruto da formação da estrutura de poder em Dourados, decorrentes da divisão dos lotes de terra em "datas", tiveram efeito não apenas sobre famílias kaiowa e ñandéva menos favorecidas, mas também sobre outras terena. Nesses termos, essa estrutura de poder não pode ser entendida como o exercício de dominação de uma etnia sobre as outras, tratando-se na verdade de disputas entre parentelas e facções para o controle de recursos, mobilização de mão de obra e obtenção de prestígio econômico e social, com a dimensão étnica constituindo apenas uma componente a mais no processo de sua emergência e consolidação.

\section{A insurgência dos dominados e o desencadear-se de um processo de descolonização}

Como visto na introdução, o avolumar-se de denúncias recebidas pelo MPF de Dourados nos inícios dos anos 2000 levou o órgão a demandar um levantamento antropológico. O intuito era o de averiguar a série de queixas e demandas dos denunciantes kaiowa e ñandéva, em vista tanto de um atendimento mais democrático e amplo por parte da Funai quanto de uma mais equânime distribuição de recursos e acesso à terra cultivável na reserva.

A principal denúncia apontava o poder centralizado nas mãos dos capitães e o fato de que o órgão indigenista os tivesse como os únicos e legítimos representantes de todas as famílias ali residentes. A apresentação, por parte dos procuradores do MPF, de uma lista indicando mais de 40 lideranças kaiowa e ñandeva que reclamavam atenção, representou uma importante base de partida para a pesquisa antropológica. Tratava-se ali, em sua maioria, de chamados cabeçantes de grupos, envolvidos em diversas atividades e projetos financiados por organismos governamentais e não governamentais, a serem desenvolvidos na reserva. Ocorre que o então alinhamento político de gestão da prefeitura de Dourados com os governos estadual e federal levou à implementação 
na reserva de atividades econômicas - como piscicultura, criação de animais de pequeno porte e produção de artesanato. Na maioria dos casos, as lideranças indígenas associavam demandas complementares ao desenvolvimento dessas atividades, relacionadas a fatores religiosos e de manifestação da etnicidade, impulsionando-se a construção de casas de rezas e a realização de rituais.

Os estudos então realizados nesse contexto - tanto para o MPF (Thomaz de Almeida; Mura, 2003) quanto depois para o MDS (Barbosa da Silva, 2006) - revelariam que em Dourados o panorama não se caracterizava por uma fragmentação organizativa ou por uma suposta anomia social. Ao contrário, o que se chegava a constatar era que, justamente por trás das demandas e reivindicações, manifestadas quase que exclusivamente por famílias kaiowa e ñandéva, bem como através da execução das citadas atividades, existia um complexo universo, caracterizado pela organização de uma pluralidade de comunidades políticas locais (Mura, 2019), que não encontrava o devido reconhecimento como tal pela Funai. Cada uma dessas comunidades era formada por grupos domésticos, constituídos por famílias de três gerações (Wilk, 1984), articulados entre si por uma liderança, geralmente seu representante, ou um cabeça da parentela (Pereira, 1999) mais expressiva dessa comunidade. A relação de cooperação entre esses grupos domésticos ocorria principalmente por laços de parentesco, mas às vezes também por relações de vizinhança e de cooperação técnico-econômica e/ou religiosa.

Como foi possível ainda notar, as comunidades estabelecidas em lugares com superfícies minimamente suficientes para desenvolver atividades agrícolas conseguiam articular maior número de grupos domésticos, chegando em alguns casos a envolver até cerca de 500 pessoas, com porcentagem de laços de parentesco entre si que alcançavam ou superavam os $80 \%$ do seu total (Barbosa da Silva, 2006). Já outras, para além do parentesco, focavam mais a atenção em atividades alternativas às agrícolas, principalmente o artesanato e práticas religiosas, com seus representantes enfaticamente reivindicando que ocorresse uma espécie de reforma agrária na reserva. Argumentavam que era injusta a existência de famílias indígenas sem terra, muitas delas com casas insalubres, em áreas alagadiças e pedregosas, enquanto poucas famílias poderosas possuíam diversos hectares na reserva, plantando soja, cultivo não voltado para a alimentação indígena. Afirmavam que a terra não era propriedade de nenhum ser humano, mas sim que fora entregue pelo Ñanderu (Nosso Grande Pai), para 
dela se fazer um bom uso - algo que, segundo os queixosos, não ocorria em Dourados.

Todas essas comunidades políticas locais reivindicavam as terras das quais a maioria de seus integrantes fora obrigada a sair, tanto na já mencionada bacia do rio Brilhante-Ivinhema quanto em outras localidades, principalmente da referida região de Lima Campo. Agregavam-se, assim, ao movimento mais amplo dos Kaiowa e dos Ñandéva de Mato Grosso do Sul, voltando-se a reivindicar a demarcação de seus territórios tradicionais (Barbosa da Silva; Mura, 2018).

Ao ressaltar a existência de cerca de 40 comunidades políticas locais em Dourados, o resultado dos trabalhos de consultoria para o MPF e o MDS colocava em evidência algumas questões que se revelarão fundamentais na tentativa de desconstrução da estrutura de poder em Dourados (que, segundo dados da então Fundação Nacional de Saúde - Funasa -, em meados dos anos 2000 possuía uma população que beirava as 10.000 pessoas), mas também em outras reservas e terras indígenas do Cone Sul de Mato Grosso do Sul, em um processo propriamente de descolonização - como se discutirá melhor adiante. Pelo seu tamanho em termos numéricos (variando de algumas poucas dezenas até algumas poucas centenas), via-se que essas comunidades se aproximavam em muito dos padrões de organização social dos próprios Kaiowa e Ñandéva, e suas lideranças apresentavam as características dos líderes tradicionais (os mboruvicha), fomentando, cada um a seu modo, uma insurgência política e moral contra as condições que dificultavam a realização do teko porã (o visto como correto modo de ser e de viver). $\mathrm{O}$ tamanho relativamente reduzido dessas comunidades revelava, portanto, que como formação comunitária era bastante equivocado falar a partir da divisão formal da reserva em duas aldeias; de fato, em termos de formação e de articulação das relações em comunidade, não se mostrava possível considerar que cada aldeia (Jaguapiru e Bororó) comportasse internamente uma única comunidade, formada por milhares de indivíduos - à época cerca de 5000 pessoas em cada lugar. O que se podia então notar era que a abrangência efetiva da legitimidade dos capitães dizia respeito a seus parentes e aliados, eles mesmos estando à frente de suas próprias comunidades políticas locais (certamente mais opulentas e, por tal razão, mais numerosas em integrantes, mas sempre menores do que a totalidade dos habitantes de cada aldeia). 
Há que se observar que esse cenário, conhecido parcialmente pelos agentes da Funai, lhes colocava o problema de como tratar com o pluralismo de representantes legítimos de todas essas comunidades. Alguns agentes argumentavam que seria impossível, por exemplo, distribuir óleo diesel para os tratores de todos os grupos presentes na reserva. Existia também uma resistência por parte dos capitães, obviamente beneficiados por suas posições na estrutura de poder, a que o modus operandi mudasse. Algumas pessoas terena, também comprometidas com essa estrutura de poder, lançavam mão das várias relações de parentesco de cunho interétnico existentes na reserva, incluindo pessoas não indígenas, para afirmar que ali todos eram indígenas, sem distinção étnica. Com isso contribuíam para legitimar uma gestão verticalizada que acabava, de fato, por negar o pluralismo e a diversidade ali existentes.

Frente a esse cenário, de demandas de real atenção ao pluralismo de representação indígena e de conflitos daí decorrentes, a partir de meados de 2000, subsidiado por todas essas informações apresentadas, o MPF começou a exigir da Funai uma mudança de atitude: a de considerar a legitimidade de todos os líderes e não apenas os capitães, exigência que os agentes do órgão indigenista, muitas vezes a contragosto e com certa resistência, tiveram que atender.

Importa notar que uma mudança na estrutura organizativa da própria Funai, efetuada nesse mesmo período, acabou se revelando complementar e importante para essa tentativa de descolonização. Ocorreu que, entre outras mudanças, a reestruturação do órgão extinguiu as chefias de posto dentro das terras indígenas (TIs), substituídas por Coordenações Locais, sediadas em centros urbanos. Isso implicava a retirada de um ator importante do interior das terras indígenas: o chefe de posto, ator que, embora nem sempre, ocorria estar intimamente ligado às estruturas de poder que se estabeleciam nessas terras.

Tomadas a partir do caso particular de Dourados e unidas a essas mudanças na estrutura da Funai, as decisões do MPF tiveram também importantes reflexos nas outras TIs habitadas pelos Kaiowa e Ñandéva do estado. Em vários lugares, os próprios indígenas começaram a perceber que era possível ver reconhecidas as lideranças de suas parentelas, não se vendo mais obrigados a perseguir a conquista do cargo de capitão para terem atendidas certas demandas. Essa mudança de percepção teve uma relevância ainda mais acentuada porque, diferentemente das reservas instituídas em território terena, onde as pessoas desse povo passaram a conseguir se relacionar com agentes do Estado por meio 
de uma pluralidade de caciques - papel este correspondente ao do capitão no interior de cada uma delas, e com a presença de um cacique geral (Ferreira, 2013, p. 271; Ladeira; Azanha, 2018), para os Kaiowa e os Ñandéva, esse modelo de organização da representação não se podia colocar naquele então. As implicações de um poder centrado na figura do capitão e a disputa para ocupar esse cargo representaram para estes últimos, principalmente com o inchaço das diminutas terras a eles concedidas, momentos caracterizados por violentas confrontações faccionais, sendo que o processo de descolonização que veio a se pôr em marcha possibilitou uma mudança de rumo de gestão política - como passaremos a ver.

\section{À guisa de conclusão: algumas reflexões sobre povos indígenas e relações de poder à luz do caso da reserva de Dourados}

$\mathrm{O}$ visto até aqui nos remete a relações de poder e a alguns conceitos que lhe são correspondentes. Neste ponto, cabe nos determos um pouco nesse aspecto.

O clássico conceito de situação colonial formulado por Balandier (1951) é de algum modo a linha-mestra que deu luz a conceitos e noções que buscavam aprimorar a capacidade explicativa de situações de colonialismo, a partir de movimentos de conquista por grupos de origem na hoje Europa, ao redor do planeta. No entanto, para além de toda a proficuidade do conceito, é se apontar uma certa limitação sua. Ao tomar o "encontro colonial" (nas palavras de Asad [1973]) fundamentalmente como fenômeno bipartido, encontramo-nos aqui diante de um problema. Conceitos que lhe vieram na esteira, como o de colonialismo interno (Casanova, 2006; Stavenhagen, 1969) e, mais recentemente, de colonialidade, chegaram num intento de caracterizar e analisar mais específica e propriamente os jogos de poder no contexto dos Estados nacionais da América de herança espanhola e portuguesa. Ocorre que todos eles, em conjunto, revelam não deixar de padecerem de uma base um tanto dicotômica, a opor blocos supostamente monolíticos e homogêneos entre si, produzindo-se portanto uma dificuldade de dar conta de interações que efetivamente comportam transversalidades, em jogos de poder a maior parte das vezes desenvolvidos por grupos que se conformam e agregam-se entre si (numa escala local e micro), a partir de interesses em comum. A rica obra de Wolf (1982) há tempos já alertava 
para o princípio teórico-metodológico de não tomar o mundo como uma mesa de bilhar, com as bolas representando unidades homogêneas e fechadas em si, ali se chocando.

De fato, o conceito de colonialismo interno se foca no fato de que as condições de dominação postas na geopolítica mundial entre colonizadores e colonizados reproduzem-se no interior de ex-colônias (Estados nacionais em formação), na ação dos segmentos dominantes com relação aos dominados. Já o conceito de colonialidade, conforme proposto por Quijano (2000), entre outros, teria suas raízes no século XVI, nos movimentos imperialistas de Espanha e Portugal na América, sendo pois algo distinto do colonialismo como evento histórico em África e Ásia - e colocando-se, nas palavras de Maldonado-Torres (2007, p. 131), propriamente como um padrão de poder. Mas, de todo modo, na colonialidade o par "colonizador versus colonizado" acaba por retomar a expressão do par "europeu versus indígena (ou negro)". ${ }^{10}$

Assim, voltando-nos então à situação empírica de Dourados, a inexistência ali de uma oposição dicotômica indígena versus não indígena, ou terena versus kaiowa e ñandéva, coloca o desafio de não se permanecer no nível da descrição de resto aqui já feita -, mas sim de realizar, em face do que foi descrito, a análise do quadro que se delineou na reserva.

Tomemos, então, o conceito de situação histórica (Pacheco de Oliveira, 1988), que tem como ponto-chave a distribuição diferencial de poder, a qual se expressa em determinado momento do tempo. Essa chave, portanto, nos possibilita vislumbrar duas situações históricas distintas aqui em pauta: uma antes e uma depois da atuação do Ministério Público Federal.

Ainda, a complexidade dos dados e do quadro expostos remete a certas transversalidades, revelando-se então profícua a análise que Gluckman (2010) fez sobre as relações entre brancos e zulus em meados da década de 1930. Com estes últimos apresentando-se como pagãos ou cristãos, desse contexto foi que

10 A análise feita por Cavalcante (2019) justamente sobre a reserva de Dourados sustentou-se exatamente sobre esses dois conceitos. Seu argumento central pode ser apreendido na seguinte passagem do trabalho (Cavalcante, 2019, p. 25): “[...] sustentado pelo padrão mental da colonialidade, o Estado brasileiro, em expressa simbiose com as elites econômica e racial nacional, age como um Estado colonialista no que tange aos povos indígenas. Um dos componentes desse colonialismo interno foi a criação das reservas indígenas destinadas aos Kaiowá e Guarani - e no caso de Dourados também aos Terena - que, na prática, liberaram todo o restante do território para a colonização (Cavalcante, 2013)." 
resultou sua noção de comunidade de cooperação, a partir da existência de interesses e objetivos em comum entre os atores sociais. Explicitando sua aproximação com a proposta de Shapera de não abordar as relações interétnicas como relações entre costumes, mas como comunidades caracterizadas por culturas heterogêneas, Gluckman ali criticou a abordagem que Malinowski fizera a esses contextos, a qual supunha uma análise separada de cada grupo étnico, para apenas depois considerar uma suposta cultura de contato. É exatamente explorando esse sentido indicado por Shapera e por Gluckman que Pacheco de Oliveira chega a formular a já referida noção de situação histórica, através da qual se torna possível apreender, em contextos temporais e sociopolíticos específicos, determinados padrões de distribuição de poder (Pacheco de Oliveira, 1988). Por outro lado, esse mesmo autor chama a atenção também para determinados padrões de interação que se vão conformando, a partir da atuação de agentes em campo, isto é, de agentes do órgão indigenista e os povos indígenas, localmente (Pacheco de Oliveira, 2006). De fato, pode-se perceber que, a partir do compartilhamento de determinados interesses e objetivos, em Dourados se estabeleceu um padrão de interação entre os poderosos indígenas (junto com seus parentes e aliados) e agentes não indígenas, padrão esse que definia para grande parte das famílias kaiowa, ñandéva e terena um modus operandi e uma situação política que os mantinham em uma posição de subjugados.

Para dar conta de tais fenômenos, é fundamental ceder espaço à dimensão doméstica e à construção de comunidades políticas locais com base no parentesco e em relações de vizinhança, permitindo visualizarem-se diferentes níveis de escala, em que a dimensão étnica, embora sumamente importante, constitui apenas um aspecto, tornando, pois, mais visível a complexidade da realidade abordada, bem como menos esquemática e dicotômica sua descrição.

Pois bem, considerando as relações descritas para Dourados, que perpassam de modo transversal distinções de caráter étnico, uma análise pertinente se revela a partir do posto em outras ocasiões como processo de dominialização (Barbosa da Silva; Mura, 2018; Mura, 2017). Com isso se quer referir a dinâmicas de produção de espaços de domínio e suas implicações organizativas, no seguinte sentido:

Se Foucault tem se servido da metáfora pastoral para discutir a governamentalidade entre os homens, considero aqui oportuno focar o ato de pastorear no 
sentido literal e técnico, como sendo uma forma de governar no sentido mais amplo, relacionando sujeitos humanos e não humanos, bem como forças e materiais de diferentes naturezas. A ação individualizante exercida pelo homem-pastor corresponde a uma tentativa de governo, com implicações significativas em termos de configuração espacial das relações num determinado contexto sócio-ecológico-territorial. Tal configuração, implicando em reações, adaptações e vínculos mútuos entre todos os sujeitos envolvidos, manifesta relações de interdependência, nos moldes indicados por Elias para compreender uma configuração social (1991) - conceito este que aqui será estendido para definir o que chamarei de configuração socioecológica. Por sua vez, sendo tal configuração o resultado de práticas de governo domesticatórias, definirei as ações que lhe dão forma como processo de dominialização. Opto aqui por um neologismo para colocar em destaque, com relação ao conceito de dominação, a dimensão além daquela social, também territorial e ecológica. O intuito é mostrar como cada sujeito humano ou não humano tende a formar espaços dominiais, tentando impor, por meio de ações diretas ou indiretas, sua vontade e poder sobre outros sujeitos ou coletividades, bem como sobre os fluxos de materiais com que estes lidam. (Mura, 2017, p. 30-31, grifo do autor).

Assim, é de se destacar os efeitos de uma primeira forma de dominialização, representada pelo que Pacheco de Oliveira (2004) denominou de processo de territorialização - entendendo com isso o modo como uma instância política, principalmente o Estado, atribui a uma população um espaço bem delimitado, para o qual dirigirá uma política de gestão. No caso específico em tela, este seria a instituição da reserva indígena, bem como a promoção de uma política integracionista e desenvolvimentista em seu interior. Ainda segundo o autor, o processo de territorialização não seria de mão única, implicando a participação ativa do grupo indígena nesse cenário político. No caso de Dourados, os principais atores seriam os grupos domésticos dominantes, integrantes não apenas das comunidades políticas locais às quais pertencem, mas também das comunidades de cooperação junto com agentes da Funai, comerciantes locais, etc. O que dizer então sobre aqueles grupos domésticos sujeitados?

Para compreender melhor sua inserção no jogo de relações, de forma complementar ao processo de territorialização desencadeado pelo Estado, temos que, segundo percebemos, focar a atenção sobre outro processo de 
dominialização, dessa vez operacionalizado pelos próprios grupos domésticos. Este seria uma ecologia doméstica (Wilk, 1997), voltada ao desenvolvimento de ações técnicas e econômicas direcionadas à reprodução desses grupos que, para tal, dão vida a estratégias políticas que consideram mais conformes com seus propósitos - geralmente norteados por tradições de conhecimento refinadas em séculos (e, para alguns aspectos, milênios) de histórias experienciais nos ambientes em que vivem. Ocorre que esses ambientes mudam ao longo do tempo e, acompanhando essas mudanças, os indígenas refinam estratégias políticas para melhor configurar repertórios de possibilidades à sua disposição, representados pela disponibilidade dos recursos almejados e sua acessibilidade (Barbosa da Silva; Mura, 2018; Mura, 2011).

A consideração dessa ecologia doméstica e o repertório de possibilidades que ela configura permite compreender, por exemplo, como famílias terena, com suas experiências agrícolas e de lida com os brancos, em Dourados, frente às políticas desenvolvimentistas promovidas pelos agentes indigenistas, tenham tirado mais vantagens do que outras. Isso não nos autoriza, contudo, a afirmar que a chave de análise possa ser colocada na dimensão étnica. Tampouco nos parece oportuno enveredar para uma suposta imanência de certos comportamentos indígenas, uma vez que esses são o resultado de experiências historicamente construídas. Com efeito, na sequência e em articulação com famílias terena, também outras famílias kaiowa e ñandéva articularam-se no seio da estrutura de poder então vigente. O que aqui se afirma é justamente o contrário, indicando como enveredar para a dicotomia não indígenas/grupo étnico $\mathrm{X}$ reduz as possibilidades de compreensão de fenômenos que manifestam vários níveis de escala de articulação política e de dinâmica territorial.

É justamente para poder alcançar esses diversos níveis de articulação que nos parece importante mudar o foco para ver como, a partir de seus interesses, os grupos domésticos se articulam em comunidades políticas locais, em grupos étnicos e em unidades políticas mais amplas. Caberá, então, dependendo de cada situação histórica considerada, ver como esses vários processos de dominialização se articulam entre si e que efeitos de poder daí resultam. No caso específico considerado, foi possível ver como, por um lado, uma política de Estado integracionista e desenvolvimentista permitiu a ascensão (e a consolidação) econômica e política de certas famílias indígenas, ao passo que um recente processo de descolonização trouxe à tona os interesses de outras, 
demonstrando a dinamicidade aqui em jogo e a importância de um enfoque histórico para sua compreensão.

Cabe, então, já nos direcionando para concluir este trabalho, fazermos algumas considerações sobre o processo de descolonização aqui apontado, cujo desencadear-se despertou nossa atenção, constituindo-se em uma das principais motivações para a escrita deste artigo. Em primeiro lugar, observamos que, com descolonização, neste caso específico não estamos pensando em um processo com características iguais mas de signo contrário ao de colonização - algo que poderia nos levar a uma ulterior esquematização dicotômica. Antes, consideramos as ações e uma legislação que podem permitir solapar os efeitos de poder de uma política tutelar implementada pelo Estado brasileiro, através de suas atividades indigenistas. São esses elementos que, introduzindo variáveis na arena política local, podem permitir reconfigurações de poder, num contraste à centralização desse poder e a suas formas de gestão pela esfera pública. Como argumenta Souza Lima (1995, 2007), a prática indigenista centra-se em uma específica tradição de conhecimento, a sertanista, parte constitutiva do processo colonial e que, no caso brasileiro, está relacionada à produção e à sistematização de um conjunto de saberes voltados a produzir técnicas de atração, pacificação e gestão dos índios. No século XX, isso redundou na instauração de uma política de tutela estatal e, para administrar os indígenas, se estabeleceu uma gestão, por efeito da territorialização em reservas, centrada no binômio capitão/chefe de posto. A tônica era (e em certa medida continua sendo) aquela de transformar os indígenas em trabalhadores nacionais, isso sendo pensado, na maioria dos casos, através de uma lógica desenvolvimentista, entendida como produtivismo, em que a centralização do poder e a gestão e exploração da mão de obra indígena são vistas como essenciais.

Há que se dizer que o estabelecimento de uma gestão tutelar assim definida, dependendo dos contextos locais e das especificidades culturais dos próprios indígenas, pode produzir configurações político-territoriais significativamente diferentes. Por exemplo, no caso da reserva terena de Cachoerinha, em Mato Grosso do Sul, Ferreira (2013) mostra como em meados dos anos 2000 os caciques dos setores (como estes indígenas denominam as aldeias no interior das terras onde estão localizados), através de um movimento faccional, davam vida a uma política de resistência com relação ao poder centralizador representado pelo binômio cacique geral/chefe de posto, permitindo assim uma 
configuração peculiar e mais simétrica na execução da gestão tutelar. Por sua vez, Ladeira e Azanha (2018) apontam como justamente Cachoerinha representaria a única terra indígena terena a preservar ainda a figura do cacique geral, com a figura dos caciques dos setores ganhando mais autonomia nas outras terras. Parece, portanto, existir entre os Terena um processo político - inclusive associado às reivindicações de recuperação de suas terras tradicionalmente ocupadas -, que contrasta os efeitos centralizadores implementado pela gestão tutelar (Amado, 2019).

Estabelecendo uma comparação, nas terras ocupadas pelos Kaiowa e pelos Ñandéva em Mato Grosso do Sul, incluindo a Reserva Indígena de Dourados, também existiram (e existem ainda) políticas de resistência nessa mesma direção, procedentes de comunidades políticas locais sujeitadas a estruturas de poder construídas em décadas de gestão tutelar. Conforme vimos ao longo deste artigo, o ingresso do MPF nessa arena política permitiu o reconhecimento e a atribuição de legitimidade a uma pluralidade de lideranças políticas, quando antes o Estado reconhecia apenas a autoridade dos capitães.

Caberia anotar, ainda, o fato de que a própria Funai veio posteriormente a fazer uma reestruturação de sua organização administrativa, entre outros aspectos extinguindo a figura do chefe de posto. Os desdobramentos desse fato (cujas consequências são também muito importantes nesse processo de descolonização) são, porém, matéria para outro trabalho.

\section{Referências}

AMADO, L. H. E. Vukápanavo: o despertar do povo terena para os seus direitos: movimento indígena e confronto político. 2019. Tese (Doutorado em Antropologia Social) - Museu Nacional, Universidade Federal do Rio de Janeiro, Rio de Janeiro, 2019.

ASAD, T. Introduction. In: ASAD, T. Anthropology and colonial encounter. New York: Humanities Press, 1973. p. 9-19.

BALANDIER, G. La situation coloniale: approche théorique. Cahiers Intenationaux de Sociologie, v. 11, p. 44-79, 1951.

BARBOSA, P. A. (En)quête de la “Terre sans Mal”: histoire et migration d'un mythe. 2014. Thèse (Doctorat en Anthropologie) - École des hautes études en sciences sociales, Paris, 2014. 
BARBOSA, P. A; MURA, F. Construindo e reconstruindo territórios guarani. Dinâmica territorial na fronteira entre Brasil e Paraguai (sec. XIX e XX). Journal de la Société des Américanistes, v. 97, n. 2, p. 287-318, 2011.

BARBOSA DA SILVA, A. Segundo relatório parcial do levantamento sócio-político-econômico e territorial em Terras Indigenas (aldeias Bororó e Jaguapiru) e Panambizinho, $e$ dos acampamentos Paso Piraju e Pakurity, do Município de Dourados(MS). Brasília: MDS, 2006. Mimeografado.

BARBOSA DA SILVA, A. Mais além da "aldeia": território e redes sociais entre os guarani de Mato Grosso do Sul. 2007. Tese (Doutorado em Antropologia Social)-Museu Nacional, Universidade Federal do Rio de Janeiro, Rio de Janeiro, 2007.

BARBOSA DA SILVA, A.; MURA, F. Territory and domestic ecology among the Kaiowa of Mato Grosso do Sul. Vibrant, v. 15, n. 2, e152402, 2018.

BARROS, E. P. Relatório do recenseamento sócio-econômico do Posto Indígena de Dourados, Mato Grosso. Brasília: Funai, 1974. Mimeografado.

BARROS, E. P.; COSTA TELLES, M. O. Relatório do recenseamento sócio-econômico do Posto Indígena de Dourados, Mato Grosso. Brasília: Funai, 1974. Mimeografado.

BENSA, A. Da micro-história a uma antropologia crítica. In: REVEL, J. (org.). Jogos de escalas: a experiência da microanálise. Rio de Janeiro: FGV, 1998. p. 39-76.

BRAND, A. O impacto da perda da terra sobre a tradição kaiowá/guarani: os difíceis caminhos da Palavra. 1997. Tese (Doutorado em História) - Escola de Humanidades, Pontifícia Universidade Católica do Rio Grande do Sul, Porto Alegre, 1997.

CARDOSO DE OLIVEIRA, R. Do índio ao bugre: o processo de assimilação dos Terêna. Rio de Janeiro: Livraria Francisco Alves Editora, 1976.

CARIAGA, D. E. Relações e diferenças: a ação política kaiowa e suas partes. 2019. Tese (Doutorado em Antropologia) - Centro de Filosofia e Ciências Humanas, Universidade Federal de Santa Catarina, Florianópolis, 2019.

CASANOVA, P. G. Colonialismo interno. In: BORON, A. A.; AMADEO, J.; GONZÁLEZ, S. (org.). A teoría marxista hoje: problemas e perspectivas. Buenos Aires: CLACSO; São Paulo: Expressão Popular, 2006. p. 395-420.

CAVALCANTE, T. L. V. Colonialidade e colonialismo interno: a política de criação de reservas indígenas no sul de Mato Grosso do Sul e algumas de suas consequências contemporâneas. In: MOTA, J. G. B.; CAVALCANTE, T. L. V. (org.). Reserva indígena de Dourados: histórias e desafios contemporâneos. São Leopoldo: Karywa, 2019. p. 21-42.

CHAMORRO, G. História Kaiowa: das origens aos desafios contemporâneos. São Bernardo do Campo: Nhanduti, 2015. 
CICOUREL, A. Teoria e método em pesquisa de campo. In: GUIMARÃES, A. Z. (org.). Desvendando máscaras sociais. Rio de Janeiro: Francisco Alves Editora, 1975. p. 87-121. ESTIGARRIBIA, A. M. V. Informe da Inspectoria do Estado do Matto Grosso. Rio de Janeiro: SPI, 1926. Documentação do Museu do Índio-Funai.

FERNANDES SILVA, J. A. Os Kaoiwá e a ideologia dos projetos econômicos. 1982. Dissertação (Mestrado em Ciências Sociais) - Instituto de Filosofia e Ciências Humanas, Universidade Estadual de Campinas, Campinas, 1982.

FERREIRA, A. C. Tutela e resistência indígena: etnografia e história das relações de poder entre os Terena e o Estado brasileiro. São Paulo: Edusp, 2013.

FERREIRA, A. C. Acumulação flexível e dialética do trabalho: reestruturação produtiva e povos indígenas na cadeia mercantil da agroindústria. In: MURA, F.; SECUNDINO, M. de A.; BARBOSA DA SILVA, A. (org.). Povos indigenas e relações de poder: olhares sobre a América do Sul. Campina Grande: EDUEPB, 2019. p. 265-284.

GLUCKMAN, M. Análise de uma situação social na Zululândia moderna. In: FELDMAN-BIANCO, B. (org.). Antropologia das sociedades contemporâneas. 2. ed. São Paulo: Ed. Unesp, 2010. p. 237-364.

LADEIRA, M. E.; AZANHA, G. Terena. Povos Indigenas no Brasil, 2018. Disponível em: https://pib.socioambiental.org/pt/Povo:Terena. Acesso em: 25 set. 2019.

LOURENÇO, R. A reserva indígena de Dourados: o derradeiro esbulho do patrimônio indígena. In: MOTA, J. G. B.; CAVALCANTE, T. L. V. (org.). Reserva indígena de Dourados: histórias e desafios contemporâneos. São Leopoldo: Karywa, 2019. p. 59-76.

MALDONADO-TORRES, N. Sobre la colonialidad del ser: contribuciones al desarrollo de un concepto. In: CASTRO-GÓMEZ, A.; GROSFOGUEL, R. (comp.). El giro decolonial: reflexiones para una diversidad epistémica más allá del capitalismo global. Bogotá: Iesco: Pensar: Siglo del Hombre Editores, 2007. p. 127-167.

MAUSS, M. Essai sur les variations saisonnières des sociétés eskimos. Étude de morphologie sociale. In: MAUSS, M. Sociologie et anthropologie. 5. ed. Paris: PUF, 1993. p. $389-477$.

MELIÀ, B.; SAUL, M. V. de A.; MURARO, V. F. O Guarani: uma bibliografia etnológica. Santo Ângelo: Fundação Missioneira de Ensino Superior, 1987.

MONTEIRO, M. E. B. Levantamento histórico sobre os índios Guarani Kaiwá. Rio de Janeiro: Museu do Índio/Funai, 2003. (Coleção Fragmentos da História do Indigenismo, 2).

MURA, F. De sujeitos e objetos: um ensaio crítico de antropologia da técnica e da tecnologia. Horizontes Antropológicos, Porto Alegre, ano 17, n. 36, p. 95-125, jul./dez. 2011. 
MURA, F. Dinâmica territorial, ecologia doméstica e processos sociotécnicos: um estudo comparativo a partir de casos entre os Kaiowa de Mato Grosso do Sul e os Tabajara da Paraíba. Projeto de pesquisa para pós-doutoramento. João Pessoa: Centro de Ciências Aplicadas e Educação, Universidade Federal da Paraíba, 2017.

MURA, F. À procura do "bom viver": território, tradição de conhecimento e ecologia doméstica entre os Kaiowa. Rio de Janeiro: ABA Publicações, 2019.

MURA, F.; BARBOSA DA SILVA, A. Relações de trabalho e colonialismo entre os Kaiowa e os Ñandéva de Mato Grosso do Sul. In: MURA, F.; SECUNDINO, M. de A.; BARBOSA DA SILVA, A. (org.). Povos indigenas e relações de poder: olhares sobre a América do Sul. Campina Grande: EDUEPB, 2019. p. 223-264.

PACHECO DE OLIVEIRA, J. O nosso governo: os Ticuna e o regime tutelar. São Paulo: Marco Zero; Brasília: MCT-CNPq, 1988.

PACHECO DE OLIVEIRA, J. Uma etnologia dos “índios misturados"? Situação colonial, territorialização e fluxos culturais. In: PACHECO DE OLIVEIRA, J. (org.). A viagem da volta: etnicidade, política e reelaboração cultural no Nordeste indígena. 2. ed. Rio de Janeiro: Contra Capa, 2004. p. 13-42.

PACHECO DE OLIVEIRA, J. Haciendo etnologia con los caboclos de Quirino: la situación etnográfica como una tríada. Boletín de Antropología Universidad de Antioquia, v. 20 , n. 37, p. 51-80, 2006.

PEREIRA, L. M. Parentesco e organização social Kaiowa. 1999. Dissertação (Mestrado em Antropologia) - Instituto de Filosofia e Ciências Humanas, Universidade Estadual de Campinas, Campinas, 1999.

PERES, S. C. Ativismo indígena, territorialização e etnicidade no médio rio Negro. Vibrant, v. 15, n. 2, e152403, 2018.

PIMENTEL BARBOZA, G. Índios Caiuás: relatório apresentado ao Sr. Dr. Inspetor Antonio Martins Vianna Estigarribia: summario de occurrencias, accusações e documentos relativos aos índios do Distrito de Dourados. [S.n.]: Rio de Janeiro, 1923. Fotocópia de manuscrito. Acervo pessoal de Rubem Thomaz de Almeida.

QUIJANO, A. Colonialidad del poder, eurocentrismo y América Latina. In: LANDER, E. (comp.). La colonialidad del saber: eurocentrismo y ciencias sociales: perspectivas latinoamericanas. Buenos Aires: CLACSO, 2000. p. 777-832.

SOUZA LIMA, A. C. de. Um grande cerco de paz: poder tutelar, indianidade e formação de Estado no Brasil. Petrópolis: Vozes, 1995.

SOUZA LIMA, A. C. de. Tradições de conhecimento na gestão colonial da desigualdade: reflexões a partir da administração indigenista no Brasil. In: BASTOS, C.; 
ALMEIDA, M. V. de; FELDMAN-BIANCO, B. (org.). Trânsitos coloniais: diálogos críticos luso-brasileiros. Campinas: Editora da Unicamp, 2007. p. 163-186.

STAVENHAGEN, R. Las clases sociales en las sociedades agrarias. México: Siglo XXI, 1969.

THOMAZ DE ALMEIDA, R. O projeto Kaiowa-Ñandeva: uma experiência de etnodesenvolvimento junto aos Guarani-Kaiowa e Guarani-Ñandeva contemporâneos do Mato Grosso do Sul. 1991. Dissertação (Mestrado em Antropologia Social) - Museu Nacional, Universidade Federal do Rio de Janeiro, Rio de Janeiro, 1991.

THOMAZ DE ALMEIDA, R. Do desenvolvimento comunitário à mobilização política: o Projeto Kaiowa-Ñandeva como experiência antropológica. Rio de Janeiro: Contra Capa, 2001.

THOMAZ DE ALMEIDA, R.; MURA, F. Levantamento situacional sobre o Posto Indígena Dourados - Mato Grosso do Sul. Dourados: MPF, 2003. Mimeografado.

THOMAZ DE ALMEIDA, R.; MURA, F. Historia y territorio entre los Guarani de Mato Grosso do Sul, Brasil. Revista de Indias, v. 64, n. 230, p. 55-66, enero/abr. 2004.

VALLE, L. Relatório para definição de um Projeto de Desenvolvimento Comunitário no Posto Indígena Dourados. Diretoria de Divisão de Desenvolvimento Comunitário. Brasília: Funai, 1975. Mimeografado.

VIETTA, K. Histórias sobre terras e xamãs kaiowa: territorialidade e organização social na perspectiva dos Kaiowa de Panambizinho. 2007. Tese (Doutorado em Antropologia Social) - Faculdade de Filosofia, Letras e Ciências Humanas, Universidade de São Paulo, São Paulo, 2007.

WILK, R. R. Households in process: agricultural change and domestic transformation among the Kekchi Maya of Belize. In: NETTING, R.; WILK, R.; ARNOLD, E. J. (ed.). Households: comparative and historical studies of the domestic group. Berkeley: University of California Press, 1984. p. 217-244.

WILK, R. R. Household ecology: economic change and domestic life among the Kekchi Maya in Belize. DeKalb: Northern lllinois University Press, 1997.

WOLF, E. Europe and the people without history. Berkeley: University of California Press, 1982.

Recebido: 30/09/2019 Aceito: 27/04/2020 | Received: 9/30/2019 Accepted: 4/27/2020 